\title{
Resiliency Process and Political Socialization among Palestinian Children Exposed to Political Traumatic Experience: An Integrative Review
}

\author{
Lobna Harazneh1, Ayman Hamdan-Mansour ${ }^{2}$ \\ ${ }^{1}$ School of Nursing, Arab American University, Jenin, Palestine \\ ${ }^{2}$ School of Nursing, The University of Jordan, Amman, Jordan \\ Email: Lobna.Harazni@aaup.edu
}

How to cite this paper: Harazneh, L. and Hamdan-Mansour, A. (2019) Resiliency Process and Political Socialization among Palestinian Children Exposed to Political Traumatic Experience: An Integrative Review. Open Journal of Nursing, 9, 303-312. https://doi.org/10.4236/ojn.2019.93029

Received: February 17, 2019

Accepted: March 25, 2019

Published: March 28, 2019

Copyright $\odot 2019$ by author(s) and Scientific Research Publishing Inc. This work is licensed under the Creative Commons Attribution International License (CC BY 4.0).

http://creativecommons.org/licenses/by/4.0/

(c) (i) Open Access

\begin{abstract}
Background: Political conflicts and wars all over the world are global concerns which directly influence the lives of people including children. Over one billion children worldwide inhabit countries or territories torn apart by armed conflict, war, or terrorism. Purpose: The purpose of this review was to identify the best evidence on the Resiliency Process and Political Socialization among Palestinian Children Exposed to Political Traumatic Experience. Methods: An integrative review was used to assess the resiliency process and political socialization among Palestinian Children Exposed to Political Traumatic Experience. Data search was between 2009 and 2019 using ProQuest, Nursing Journal Publications, EBSCO, Jordanian Database for Nursing Research, WHO online library, scholar Google scholar, science direct, and PubMed. A total of 8 articles met the eligibility criteria. Results: The eight reviewed articles adopted descriptive analytic and cross-sectional studies. Themes were: Impact of psychological trauma on children, Political socialization process and Resiliency among children. Conclusion: Reviewed articles regarding children reaction to trauma and resiliency process showed that children varied in their responses. The studies showed that children were vulnerable to psychological harms and consequences of trauma that might include PTSD and others behavioral problems. At the same time, the studies confirmed that despite the harmful consequences they had positive adaptation and abilities to resist.
\end{abstract}

\section{Keywords}

Resiliency Process, Political Socialization, Palestinian Children, 
Political Traumatic Experience

\section{Introduction}

Political conflicts and wars around the world affect the lives of people, including children, directly throughout the world. More than a billion children worldwide live in countries or territories destroyed by armed conflicts, wars or terrorism [1].

Palestine lives in political conflict since 1948. Palestinians children are one of the largest populations living in political conflict and ongoing crisis [2]. This generally makes children vulnerable to higher levels of negative effects on such events. Detention of children is a form of exposure to a high stressor and a clear example of violations of children's rights. Palestinian children have been detained under inhumanist conditions repeatedly.

Several factors contribute to deciding whether a child is affected negatively or positively by this experience, such as: physical and psychological safety, supportive relationships, opportunities to belong, positive social standards, opportunities for building skills, integration of family, school, and community efforts. All these factors are considered as supportive protective factors, in addition to family and community conceptualization of trauma, political socialization among child environment, age, and previous experiences are also among these factors [3]. Children who are psychologically well equipped and who use effective coping are more likely to be healthier psychologically. Their positive adaptation enables them to develop the resilience that constitutes their event experience and contributes positively to the psychological consequences of the protective factor [3]. On the other hand, children who do not have such positive and protective factors are more likely to be severely harmed by these events, and these children may also be unable to cope with the post-trauma situation [4]. Therefore, the purpose of this review was to identify the best evidence of the process of resilience and political socialization among Palestinian children exposed to political trauma.

\section{Materials and Methods}

In this review, the search was performed by different international databases including ProQuest, Nursing Journal Publications, EBSCO, Jordanian Database for Nursing Research, and WHO online library, scholar Google scholar, science direct, and PubMed using the keywords of "political trauma", "resiliency", "Palestinian children", "post-traumatic", "military detention of children", "children under occupation", and "socialization".

Initially, a new keyword was added separately for each new search until all keywords were included. These words were later searched in combination. However, the search process was limited to the following criteria for inclusion: 1) 
written in English, 2) published between 2009 and 2019, 3) specifically related to the resilience process and political socialization of children exposed to Political Traumatic Experience, and 4) no restriction on article type. Studies including other age groups were excluded.

Resources have been clustered according to their suitability for study. Some studies were considered for problem statement, for example, while others were considered for design, significance or supporting evidence. The main result is the impact of psychological trauma on children, the process of political socialization and children's resilience. However, review papers and incomplete reports in the form of editorials, opinion pieces, and conference abstracts have been excluded.

In addition, a total of 350 articles were retrieved and their title abstracts were initially assessed. Only 247 were found to be related to the subject of interest after the evaluation and removal of the duplicated articles. Following a secondary assessment, the related articles were then printed and read in full, and nine articles were precisely identified to cover the inclusion criteria. As a result, the review included these nine articles (see Figure 1). Among the nine articles, seven articles affected children by psychological trauma and two articles were the process of political socialization and children's resilience.

The results of each study were considered with codes for literature identification, summary, synthesis and inferences and discussion of findings to clarify the themes of interpretation. Articles selected for retrieval were assessed for methodological validity by two independent reviewers prior to inclusion in the review. Critical appraisal assessment and review was done with agreement between the

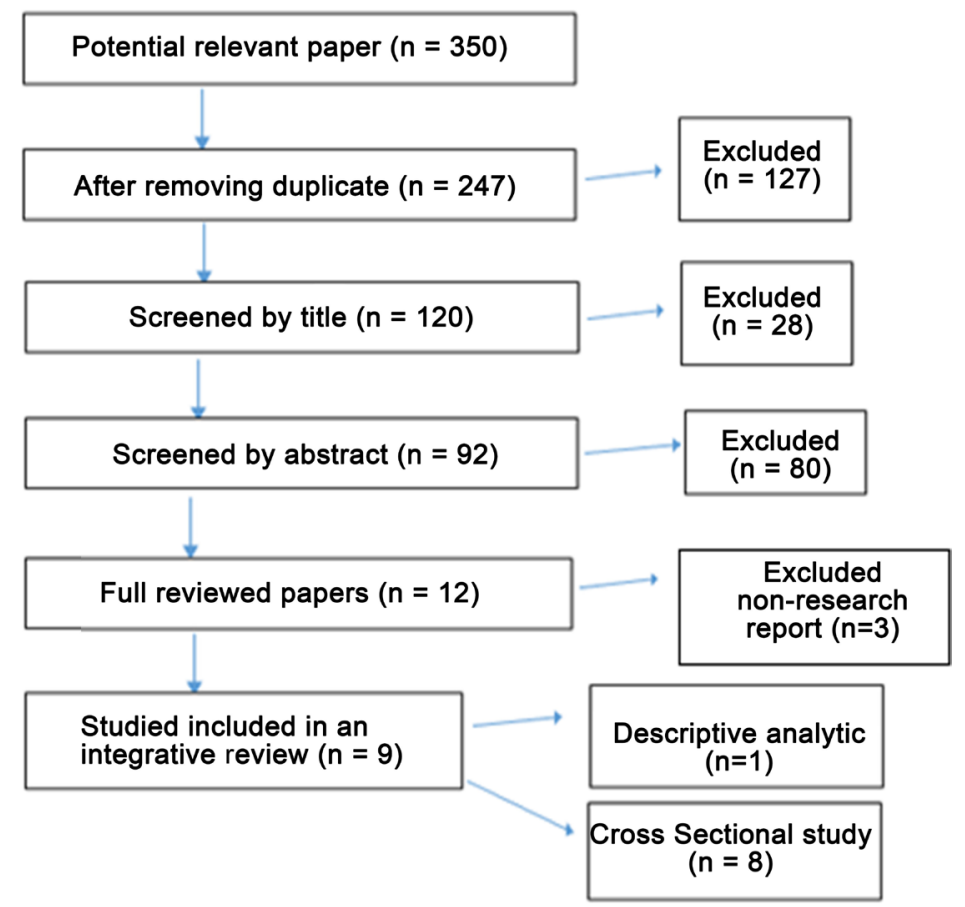

Figure 1. Search strategy and outcomes. 
reviewers and a third reviewer was consulted when needed. Data was extracted from the literature included in the review using standardized data extraction using specific details about the interventions, populations, study methods and outcomes of significance to the aim of the review. Then to display the data, all summarized pages were collected in a one matrix by using word sheet.

\section{Results}

Nine relevant articles have been reviewed. From each article the following data have been extracted: study purpose, design, sample, and findings (Table 1). Then, authors compared articles, interpreted findings to identify themes, and grouped them based on their similarities. Overall, the nine reviewed research reports published between 2009 and 2019 (one descriptive analytic study, and eight cross-sectional studies). However, to address the purpose of this review, the findings (Palestinian Children Exposed to Political Traumatic experience) were categorized into common themes, using a color-coding method to highlight similarities across the literature. The two main themes were the following: 1) impact of psychological trauma on children, and 2) political socialization process and resiliency among children.

\section{Theme One: Impact of psychological trauma on children}

In a study included 200 parents and 200 children aged 9 - 18, who were evaluated on the basis of a self-fulfilled questionnaire, showed that the average traumatic experience for parents was 8.42, the prevalence of PTSD (posttraumatic stress disorder) in parents was $60 \%$; anxiety disorder $26.5 \%$. For children, the average number of traumatic events was 7.88, the prevalence of PTSD in children was $70.1 \%$, anxiety disorder (33.9\%), general mental health problems rated by parents $(42.7 \%)$, behavioral disorder $(36.8 \%)$, hyperactivity $(22.8 \%)$, emotional problems $(24.4 \%)$, problems with peers $(60.1 \%)$, and social problems (20.2\%). There was correlation between trauma of children and PTSD of children, intrusion, avoidance, and arousal. There are no gender differences in PTSD in both parents and children. PTSD parents were associated with PTSD children. Children's PTSD was significantly associated with total traumatic events of parents, anxiety of parents, of PTSD of parents, intrusion symptoms of parents, avoidance, and arousal symptoms. Children's anxiety was also significantly linked to parents' anxiety [5].

Another study carried out by 400 students ( 200 boys and 200 girls) to determine the relationship between war trauma and post-traumatic stress disorder, social support and family support for adolescents in the Gaza Strip. The study showed that the average reported traumatic experiences were 12.19. More than girls were exposed to boys. The study showed that $25 \%$ of adolescents reported partial PTSD and 9.3\% had full PTSD criteria. More PTSD was reported by boys than girls. The social support median was 83 . There was less total social support for adolescents aged 13 than the older group. The mean amount of family support was 97.33 , the acquisition of social support was 28.62 , reframing was 26.18 , 
Table 1. A summary of the characteristics of the included articles.

\begin{tabular}{llll}
\hline Authors & Purpose & Sample Size & Design \\
\hline Thabet, & to investigate types of traumatic events & $\mathrm{N}=358$ & Descriptive \\
El-Buhaisi & due to war on Gaza experienced by & adolescents aged 15 analytic \\
and Vostanis & Palestinian adolescents in relation to & to 18 years old age. & \\
$(2014)$ & PTSD and anxiety and coping strategies & & \\
& as mediating factor. &
\end{tabular}

Main Findings

The study showed that $11.8 \%$ of adolescents reported no PTSD, $24.2 \%$ reported less than two clusters of symptoms, and $34.31 \%$ reported symptoms meeting criteria for partial PTSD, while $29.8 \%$ reported symptoms meeting criteria for full PTSD. Palestinian adolescents mainly cope commonly by developing social support, investing in close friends, and/or engaging in demanding activities. Adolescents with PTSD had coping by ventilating feelings, developing social support, avoiding problems, and Adolescents with less PTSD had looking more for solving his family problems.

Massad, Javier Examined the factors associated with Nieto, Palta, resilience and vulnerability in mental Smith, Clark health in the Gaza Strip in 2007. and Thabet (2009)

Al-Sheikh and To find the relationship between Thabet (2017) trauma due to war and post-traumatic stress disorder, social, and family support among adolescent in the Gaza Strip.

Thabet, To explore the relationship between Thabet and trauma due to war, post-traumatic Vostanis stress disorder, and fears among (2018) Palestinian children in the Gaza Strip.
$\mathrm{N}=350$ Children $\quad \mathrm{A}$ of kindergartens cross-sectional 3-6 years old, were study assessed for growth and their mothers.

$\mathrm{N}=400$ students A Cross section The study showed that mean traumatic experiences (200 boys and 200 study girls). selected randomly cross-sectional from the entire study Gaza Strip.

Factors associated with resilience were maternal rated good health, higher maternal level of education, and less child exposure to traumatic events. Factors associated with vulnerability were poor maternal mental health, and male gender.

reported was 12.19 . Approximately $25 \%$ of adolescents reported partial PTSD and 9.3\% had full criteria of PTSD. There was positive correlation between total traumatic events and PTSD, intrusion and avoidance.

Results showed that $12.4 \%$ of children had reported full criteria of post-traumatic stress disorder. No differences in exposure to trauma according to place of residence or family monthly income. There
$\mathrm{N}=449$ children $\quad \mathrm{A}$ was positive relationship between exposure to traumatic events and post-traumatic stress disorder and fears. Also, fears were associated with total post- traumatic stress disorder and all subscales.

$\mathrm{N}=374$ children Cross-sectional For PTSD, 1.3\% of children showed no PTSD, 7.2\% aged 6-16 years study reported mild PTSD reactions, $29.9 \%$ showed moderate PTSD reactions, and $61.5 \%$ showed severe to very severe PTSD reactions. Trauma exposure was significantly associated with PTSD.

$\mathrm{N}=400$ secondary Cross-sectional The results showed that $24 \%$ adolescents had

school students study (200 males and 200 females).

Abdel Aziz To determine the effect of shelling and $\mathrm{N}=200$ parents and Vostanis other traumatic events on mental health and 200 children (2017) of parents and children. age 9 - 18 years who were assessed by self-completed questionnaire. partial PTSD, and $10.5 \%$ had full criteria of PTSD.

The results also showed that adolescents had above moderate level of resilience with mean score 80.48 .

Cross-sectional The results estimated mean traumatic experiences for study parents were 8.42, prevalence of PTSD in parents was $60 \%$; anxiety disorder $26.5 \%$. For children, mean traumatic events were 7.88; prevalence of PTSD in children was $70.1 \%$.

There was correlation between trauma of children and PTSD of children, intrusion, avoidance, and arousal. Parents PTSD were associated with their children PTSD. PTSD of children was significantly associated with total traumatic events of parents, anxiety of parents, of PTSD of parents, intrusion symptoms of parents, avoidance, and arousal symptoms. 


\section{Continued}

Thabet and To explore the types and severity of the $\mathrm{N}=319 \quad$ Cross-sectional The study showed that $58.3 \%$ reported life

Thabet (2017) traumatic experiences, and to estimate adolescents ages 12 study the prevalence rate of post-traumatic to 18 years stressors, mean stressors was 4.07. Mean traumatic events. events reported was 3.7 .

The study results showed that $29.5 \%$ had partial post-traumatic stress disorder and $23.5 \%$ had full criteria of post-traumatic stress disorder.

Al Ghalayini To investigate the relationship between and Thabet war trauma and anxiety and

$\mathrm{N}=399$ mothers $\quad$ Cross-sectional

The mean number of traumas experienced by (2017). posttraumatic stress disorder (PTSD) among preschool and their preschool study preschool children was 8.3. PTSD prevalence was children who were enrolled in children in the Gaza Strip. $6 \%$ with scores higher in children aged five and older.

There were significant associations between trauma and PTSD and anxiety as well as a significant association between PTSD and anxiety.

seeking spiritual support was 14.26 , mobilizing family to acquire. Positive correlation was found between total traumatic events and PTSD, intrusion and prevention. Although total traumatic events have been negatively correlated with family management and social support, there was a positive correlation between PTSD and social assistance and support for families [6].

Another, a descriptive analytical study of 358 adolescents aged 15 to 18 years aimed at investigating types of traumatic events caused by the war in Gaza suffered by Palestinian adolescents in regards to PTSD and strategies of anxiety and coping as a mediating factor. The study showed that the average traumatic event in adolescents was 13.34. The adolescents ' traumatic experiences reported in order were: $90.8 \%$ watched mutilated bodies on TV, $88.5 \%$ heard heavy artillery shelling of the area, $86.6 \%$ saw signs of shelling on TV. The results showed that the average total anxiety was 41.18 , the obsessive compulsive subscale was 8.90 , the generalized subscale of anxiety was 4.46 , social phobia was 6.99 , anxiety about separation was 6.16, fear of physical injury was 5.48, and panic / agoraphobia was 5.4. The results showed that girls had more problems with anxiety than boys, including all subscales of anxiety. Regarding PTSD, the study showed that 11.8 percent of adolescents did not report PTSD, 24.2\% reported less than two clusters of symptoms, and $34.31 \%$ reported that symptoms met the criteria for partial PTSD, while $29.8 \%$ reported that symptoms met the criteria for full PTSD according to DSM-IV-TR. The results showed that more PTSD was reported by girls than boys. Palestinian teenagers usually cope with social support, invest in close friends and/or engage in demanding activities. The study showed that teenagers experienced traumatic experiences developed less social support and asked for more professional support as strategies for coping. Teenagers with PTSD were able to cope with feelings by ventilating, developing social support, avoiding problems, and teenagers with less PTSD were looking more to solve their family problems. Anxious adolescents ventilated feelings, developed social support and carried out demanding activities. Teenagers with less anxiety sought more spiritual support [3]

A cross-sectional study conducted on 449 randomly selected children from 
the entire Gaza Strip. Children aged from 7 to 18 years explore the relationship between trauma due to war, PTSD, and fears among Palestinian children in the Gaza Strip. Overall, Palestinian children reported a range of 0 to 17 traumatic events, with a mean number of $3.59(\mathrm{SD}=2.92)$. There were no significant differences between boys and girls in reporting exposure to traumatic events. Children commonly reported fears such as: $56.2 \%$ said that they scream when they see and hear the plane in the air, 54.3\% said that had fears of strangers, 50\% said that are afraid of heights, 47.4 said they afraid when their parents leave and they stay alone at home. Children reported from no fears to 19 types of fears, mean fears were 6.66. Regard prevalence of post-traumatic stress disorder, 12.4\% of children had reported full criteria of post-traumatic stress disorder. No differences in exposure to trauma according to place of residence or family monthly income. There was positive relationship between exposure to traumatic events and post-traumatic stress disorder and fears. Also, fears were associated with total post- traumatic stress disorder and all subscales [7].

Another cross-sectional study to find the relationship between war traumatic experiences was due to war on Gaza, PTSD, and traumatic grief in Palestinian children. The sample included randomly selected 374 children aged 6 - 16 years. Children completed measures of experience of traumatic events (Gaza Traumatic Checklist), Child Post Traumatic Stress Reaction Index, and Traumatic Grief inventory. Results showed that Palestinians children experiences variety of traumatic events. No sex differences in reporting trauma. Mean traumatic events reported by children was 12.80 traumatic events. The study showed that $9.3 \%$ of the participants lost someone during the war. Mean traumatic grief in boys was 19.96 and 18.29 in girls. For PTSD, 1.3\% of children showed no PTSD, 7.2\% reported mild PTSD reactions, $29.9 \%$ showed moderate PTSD reactions, and $61.5 \%$ showed severe to very severe PTSD reactions. Trauma exposure was significantly associated with PTSD. No sex differences in PTSD [8].

In a cross-sectional study, 399 mothers and their pre-school children enrolled in kindergartens in the Gaza Strip investigated the relationship between war trauma and anxiety and PTSD. The age of children ranged from three to six years. Results showed that the most commonly reported traumatic experiences by mothers for their children were: hearing shelling of the area by artillery (95.5\%), hearing loud noises from drones (89.2\%) and seeing mutilated bodies on TV (81.2\%). The mean number of traumas experienced by preschool children was 8.3 . PTSD prevalence was $6 \%$ with scores higher in children aged five and older. The mean for total anxiety was 49.84 , generalized anxiety was 10.7 , social anxiety was 8.4 ; specific phobia was 21.1 , and separation anxiety was 9.65 . There were significant associations between trauma and PTSD and anxiety as well as a significant association between PTSD and anxiety [9].

Furthermore, a study on 319 adolescents ages 12 to 18 years to find the most common stressors facing the adolescents in the Gaza Strip, to explore the types and severity of the traumatic experiences, and to estimate the prevalence rate of 
post-traumatic events. The study showed that $58.3 \%$ reported life stressors, mean stressors was 4.07. Boys significantly reported more life stressors than girls. Mean traumatic events reported was 3.7. Boys report more traumatic events than girls. The study results showed that $29.5 \%$ had partial post-traumatic stress disorder and $23.5 \%$ had full criteria of post-traumatic stress disorder [10].

In general, most studies in the Occupied Palestinian Territories have highlighted the high rate of dysfunction and maladaptation in Palestinian children and have actually reported a high prevalence of common mental health problems and more serious disorders.

Theme Two: Political socialization process and resiliency among children

A cross-sectional study conducted on children 3 - 6 years old in the Gaza Strip, the region most adversely affected by political conflict and deprivation in the Palestinian Territory. The study aimed to examine the factors associated with resilience and vulnerability in mental health in the Gaza Strip in 2007. The Children selected from a random sample of kindergartens $(3-6$ years old, $\mathrm{N}=$ 350) were assessed for growth and their mothers. Results showed that Factors associated with resilience were maternal rated good health, higher maternal level of education, and less child exposure to traumatic events. Factors associated with vulnerability were poor maternal mental health, and male gender [11].

Another cross-sectional study conducted to determine the relationship between traumatic experience, posttraumatic stress disorder, resilience, and posttraumatic growth among adolescents in Gaza Strip. The sample consisted of 400 secondary school students (200 males and 200 females) from the seven directorates of the Gaza Strip. Their age ranged between 15 - 18 years with mean age 16.67 years. Descriptive, analytic cross-sectional design was used. The results showed that the most common traumatic events were hearing the voices of the bombing on different areas (92.3\%), listening to the sound of drones constantly (86.3\%), and hearing the death of a friend or neighbor during the war (79.5\%), and $13 \%$ of adolescents had mild trauma, $39.8 \%$ had moderate trauma, and 47.3\% had severe trauma. Also, the results showed that $24 \%$ adolescents had partial PTSD, and $10.5 \%$ had full criteria of PTSD. The results also showed that adolescents had above moderate level of resilience with mean score 80.48 [12].

\section{Discussion}

It is assumed that the impact of psychological trauma on children is similar and even worse than adults. Previous studies have also examined the effect of political events and war on children, most studies have confirmed that exposure to war is linked to a high level of personality disorder, maladaptive behaviors such as smoking and drinking, Mayer's night and poor school performance [13]. Other studies addressed positive adaptation among Palestinian children (resilience, normalization of abnormal and high political awareness). Research shows that trauma does not necessarily lead to psychopathology, and that resilience is a rule rather than an exception. Traumatic experience can enhance the child's 
ability to cope with stress if the trauma is associated with other surroundings [14]. PTSD of children was significantly associated with total traumatic events of parents, anxiety of parents, of PTSD of parents, intrusion symptoms of parents, avoidance, and arousal symptoms [5]. There were differences in reporting PTSD between girls and boys [3] [6] [8] [10], but other studies reporting no differences between them [7]. Maternal - rated good health, higher maternal education and less exposure to traumatic events were factors associated with resilience. Poor maternal mental health and male gender were associated with vulnerability [10]. Adolescents had above moderate level of resilience [11].

Palestinian kids survive traumatic events. Despite the circumstances that surround them, they stand up, adapt, bounce back, recover and try to overcome all difficulties [15]. They added that this ability has been built over the years and in Palestinian society due to many contextual factors.

\section{Conclusions}

Reviewed articles on the reaction of children to trauma and resilience have shown that the responses of children vary. Studies have shown that children are vulnerable to psychological damage and trauma consequences, including PTSD and other behavioral problems. At the same time, studies examining traumatic Palestinian children, in particular political trauma, confirmed that they had positive adaptation and resistance despite the harmful consequences. Most of these studies questioned factors that promoted adaptation and resilience among Palestinian traumatized children. Other studies also ignore the resilience development process, which provides strong evidence and requires further resilience research. The revised articles did not adequately highlight the process in which Palestinian children demonstrated high resilience. In health and psychological research, children are exposed to political traumas such as military detention in order to adopt a qualitative technique to explore and understand more about such a phenomenon. Since this type of trauma has a special interpretation among the Palestinian community, it is important to address and explore the role of political socialization in the development of resilience.

The gap existing in reviewed articles was on addressing the role of political socialization in developing resiliency process particularly for political trauma such as being under military detention. As this type of trauma has special interpretation among Palestinian community, it's critical to address and explore that role of political socialization on developing resiliency.

Furthermore, little attention is given in the literature on the issue of children detention and the effect of this experience on children after being released.

\section{Conflicts of Interest}

The authors declare no conflicts of interest regarding the publication of this paper. 


\section{References}

[1] Chrisman, A.K. and Dougherty, J.G. (2014) Mass Trauma: Disasters, Terrorism, and War. Child and Adolescent Psychiatric Clinics, 23, 257-279.

https://doi.org/10.1016/j.chc.2013.12.004

[2] Al-Ajarma, Y. (2010) The Role of the Arts toward Healing Trauma and Building Resilience in the Palestinian Community. Doctoral Dissertation, Lesley University, Cambridge.

[3] Thabet, A., El-Buhaisi, O. and Vostanis, P. (2014) Trauma, PTSD, Anxiety, and Coping Strategies among Palestinians Adolescents Exposed to War on Gaza. The Arab Journal of Psychiatry, 25, 71-82.

[4] Pfefferbaum, B., Nitiéma, P., Jacobs, A.K., Noffsinger, M.A., Wind, L.H. and Allen, S.F. (2016) Review of Coping in Children Exposed to Mass Trauma: Measurement Tools, Coping Styles, and Clinical Implications. Prehospital and Disaster Medicine, 31, 169-180. https://doi.org/10.1017/S1049023X16000169

[5] Abdel Aziz, M.T. and Vostanis, P. (2017) Effect of Trauma on Mental Health of Parents and Children in the Middle Area of the Gaza Strip. Journal of Intellectual and Developmental Disability, 3, Article ID: 555619.

[6] Al-Sheikh, N.A. and Thabet, A.A. (2017) Post-Traumatic Stress Disorder Due to War Trauma, Social and Family Support among Adolescent in the Gaza Strip. IOSR Journal of Nursing and Health Science, 3, 10.

[7] Thabet, A.M., Thabet, S. and Vostanis, P. (2018) The Relationship between Trauma Due to War, Post Traumatic Stress Disorder and Fears among Palestinian Children. EC Paediatrics, 7, 171-178.

[8] Thabet, A.A., Tawahina, A.A., Punamäki, R.L. and Vostanis, P. (2015) Trauma, PTSD, and Traumatic Grief among Palestinian Children. SM Journal of Community Medicine, 1, 1011.

[9] Al Ghalayini, H. and Thabet, A.M. (2017) The Relationship between War Trauma and Anxiety and Posttraumatic Stress Disorder among Preschool Children in the Gaza Strip. Arab Journal of Psychiatry, 28, No. 1.

[10] Massad, S., Javier Nieto, F., Palta, M., Smith, M., Clark, R. and Thabet, A.A. (2009) Mental Health of Children in Palestinian Kindergartens: Resilience and Vulnerability. Child and Adolescent Mental Health, 14, 89-96. https://doi.org/10.1111/j.1475-3588.2009.00528.x

[11] Murad, K. and Abdel, A.M. (2017) The Relationship between Traumatic Experience, Posttraumatic Stress Disorder, Resilience, and Posttraumatic Growth among Adolescents in Gaza Strip. Glob J Intellect Dev Disabil.

[12] Thabet, A.M. and Thabet, S.S. (2017) Stress, Trauma and Post-Traumatic Stress Disorder among Adolescents in the Gaza Strip. Journal of Trauma and Critical Care, 1, 25-33.

[13] Danese, A. and Lewis, S.J. (2017) Psychoneuroimmunology of Early-Life Stress: The Hidden Wounds of Childhood Trauma? Neuropsychopharmacology, 42, 99. https://doi.org/10.1038/npp.2016.198

[14] Ely, R. and Gleason, J.B. (2017) Socialization across Contexts. The Handbook of Child Language, 251-276. https://doi.org/10.1111/b.9780631203124.1996.00010.x

[15] Khamis, V. (2012) Posttraumatic Stress and Worry as Mediators and Moderators between Political Stressors and Emotional and Behavioral Disorders in Palestinian Children. International Journal of Psychology, 47, 133-141.

https://doi.org/10.1080/00207594.2011.598524 